\title{
POST-TRAUMATIC STRESS DISORDER IN COVID-19 PCR POSITIVE PATIENTS; ITS FREQUENCY AND PSYCHOSOCIAL RISK FACTORS HAVE BEEN OBSERVED IN ENT AND NEUROLOGY OUTPATIENT'S CLINICS
}

\author{
Kausar Mahmood, Shanila Feroz, Iqbal Hussain Udaipurwala*, Aaqil Anwar, Owias Khan Tareen, Zaib Un Nisa \\ United Medical and Dental College, Karachi Pakistan, *Bahria University Medical \& Dental College, Karachi Pakistan
}

\section{ABSTRACT}

Objective: To find out the occurrence and psychosocial risk factors of post-traumatic stress disorder in COVID-19 polymerase chain reaction (PCR) positive patients presented to ENT and neurology clinics of a tertiary care hospital.

Study Design: Cross-sectional study.

Place and Duration of Study: Creek General Hospital, Karachi, Pakistan, from Sep to Dec 2020.

Methodology: Total 60 patients with positive COVID-19 PCR test were included. After taking written and informed consent, they were evaluated using a semi-structured questionnaire. Questionnaire comprises of four main parts; first part includes demographic data, second part includes information about the course of COVID-19 in patient and other members of family, third part comprised of reasons of anxiety during COVID-19 and fourth part consist of Impact of Event Scale-revised (IES-R). Data was entered and analyzed through SPSS-23.

Results: Out of total 60 patients, $36(60 \%)$ had post COVID stress disorder. Females were affected more than the males $(63 \%$ vs. $57 \%)$, above 50 years of age were affected more than below 50 years of age $(81 \%$ vs $52 \%)$, singles were affected more than married ( $72 \%$ vs $38 \%$ ) and lower socio-economic status were affected more than higher $(65 \%$ vs $50 \%)$.

Conclusion: PTSD was observed as long-term psychiatric problem leading to significant morbidity and mortality in patients with COVID-19 infection.

Keywords: COVID-19, Impact of Event Scale-revised, PCR positive patients, Post-traumatic stress disorder.

How to Cite This Article: Kausar M, Shanila F, Udaipurwala IH, Anwar A, Khan O Tareen, Nisa ZU. Post-Traumatic Stress Disorder in COVID-19 PCR Positive Patients; Its Frequency and Psychosocial Risk Factors Have Been Observed in Ent and Neurology Outpatient's Clinics. Pak Armed Forces Med J 2021; 71 (Suppl-3): S508-511. ～Doi: https://doi.org/10.51253/pafmj.v1i1.7918

This is an Open Access article distributed under the terms of the Creative Commons Attribution License (https://creativecommons.org/licenses/by-nc/4.0/), which permits unrestricted use, distribution, and reproduction in any medium, provided the original work is properly cited.

\section{INTRODUCTION}

Since its origin in December 2019 in China, the novel corona virus disease (COVID-19) is spreading rapidly globally and the morbidity and mortality associated with this is challenging for the nations by several means. ${ }^{1,2}$ With more than 200 countries and territories effected with this virus, it is still dubious what effects this virus is going to have on human health in long term. ${ }^{6}$ All the measures initially taken for the betterment of physical wellbeing and treatment of COVID confirmed patients. However, it's delayed psychological effects on patient's mental health including PostTraumatic Stress Disorder is still unknown. ${ }^{3}$

Post-traumatic stress disorder (PTSD) is a common mental disorder which is a consequence of a wide collection of traumatic events like war orpersonal event like road traffic or accidents that can result in serious misery, anguish and disability. ${ }^{7}$ Main symptoms of Post-traumatic stress disorder includes persistent intrusion symptoms, persistent avoidance of stimuli, negative alterations in cognition or mood, and

Correspondence: Dr Shanila Feroz, ENT-Head \& Neck Surgery, United Medical and Dental College, Karachi Pakistan marked alterations in arousal and reactivity, all associated with the prior traumatic event. ${ }^{8}$

Due to ambiguity about the well-being, patients who are suffering from COVID-19 mayhave high incidence of PTSD. Similarly, severe acute respiratory syndrome (SARS) and Middle East Respiratory Syndrome Epidemic (MERS) have caused severe PTSD. It is expected that COVID-19 pandemic will result inearly and delayed mental health problems,, 5 and survivors of COVID-19 will live under the shadow of past trauma. Previous studies during the pandemic of SARS have shown that PTSD was found in $25.6 \%$ of survivors, which is quite high in number. ${ }^{9}$

We aim to determine the frequency and long-term psycho-social risk factors in the form of post-traumatic stress disorder in patients with confirmed COVID-19 PCR positive patients visited in ENT and Neurology outpatient clinic of a tertiary care hospital of Karachi.

\section{METHODOLOGY}

The sample included 60 participants witha positive nasopharyngeal swab for SARS-CoV-2 with variable severity of infection. Participants were recruited from Neurology and ENT Specialty outpatient clinics 
of Creek General Hospital, Karachi, from September to December 2020. These patients were presented with Otoneurological disorders likeof flu, fever, sore throat, non productive cough, chest congestion, epistaxis, complete nasal obstruction leading to breathing difficulty, loss of taste and smell, tinnitus, equilibrium disorders and persistent headache.

Inclusion Criteria: Inclusion criteria consists of individuals above 18 years of age, literate and individual who had COVID-19 PCR positive.

Exclusion Criteria: Exclusion criteria consists of individual having any previous history of major neurological or psychiatric condition or previously using or had used any drugs for any neurological or psychological disease.

Written and informed consent was taken from each patient who agreed to participate in the study. A semi-structured questionnaire was used to assess PSTD. Questionnaire comprises of 4 main parts; In first part demographic data was included, in second part the information about course of COVID-19 in patient and other members of family was incorporated, third part of questionnaire comprised of reasons of anxiety during COVID-19 and in fourth part Impact of Event Scale-Revised (IES-R) was used to assess the degree of distress. The IES-R offers an organized way for a patient to communicate his or her distress where otherwise he or she is not able to describe it. It is a self-report that measures distress caused by atraumatic event. This scale is a revised version of its older versionand contains 22-item that are rated on a 5-point scale ranging $0-4(0=$ not at all and $4=$ extremely).

All the data was entered and analyzed through SPSS version 23. Scores of post-traumatic stress (PTSD) disorder was measured. Mean and standard deviation were calculated for the quantitative variables including PTSD scores. Effect modifiers like gender, age, marital status, socioeconomic status, and educational level were controlled through stratification. After stratification chi-square test was applied and $p$-value 0.05 was considered as significant.

\section{RESULTS}

Out of 60 participants 36 of the participants i.e., $60 \%$ with COVID-19 PCR positive showed PTSD symptoms which were significant and refer for further management to psychiatric department. Results also showed female population $(63 \%)$ with higher number as compared to male (57\%) with PTSD. It is also observed that PTSD is more common among participants who were above 50 years of age i.e., $81 \%$ and is more evident in individuals who were single that is in 28 $(72 \%)$ as compared to those who are married 38\% (Table-I). Most of the participants in our study were stable enough to be isolated at home and observation showed higher percentage of PTSD symptoms i.e. $80 \%$. Total numbers of participants who suffer beingin isolation, were 39. Out of those 28(72\%) suffered from PTSD later. Participants with low socio-economic status showed higher percentage of PTSD i.e., 65\% (26). Only 9 participants in our study admitted due to anxiety and panic attack due to COVID-19 infection and out of these, $8(89 \%)$ of participants developed PTSD later. Our study results showed that out 7 participants with pre COVID-19 infection anxiety, 6 (86\%) developed PTSD symptoms later. In our study, PTSD symptoms were more common in patients who were isolated for less than 14 days then who were isolated for longer duration of more than 20 days i.e., 20 (74\%) and 6 $(55 \%)$ and respectively than those who had isolation period of $15-20$ days (45\%).

\begin{tabular}{|c|c|c|c|c|c|}
\hline & & Total & \begin{tabular}{|c|} 
Non- \\
PTSD $(\%)$
\end{tabular} & $\begin{array}{c}\text { PTSD } \\
(\%)\end{array}$ & $\begin{array}{c}\text { Chi Sq } \\
p \text {-value }\end{array}$ \\
\hline \multirow{2}{*}{ Gender } & Male & 30 & $13(43)$ & $17(57)$ & \multirow{2}{*}{0.60} \\
\hline & Female & 30 & 11 (37) & $19(63)$ & \\
\hline \multirow{2}{*}{$\begin{array}{l}\text { Marital } \\
\text { status }\end{array}$} & Unmarried & 39 & $11(28)$ & $28(72)$ & \multirow{2}{*}{0.011} \\
\hline & Married & 21 & $13(62)$ & $8(38)$ & \\
\hline \multirow{2}{*}{$\begin{array}{l}\text { Age } \\
\text { (Year) }\end{array}$} & $<50$ & 44 & $21(47.7)$ & $23(52.2)$ & \multirow{2}{*}{0.09} \\
\hline & $>50$ & 16 & $3(19)$ & $13(81)$ & \\
\hline \multirow{2}{*}{$\begin{array}{l}\text { Socio- } \\
\text { economic } \\
\text { status }\end{array}$} & Stable & 20 & $10(50)$ & $10(50)$ & \multirow{2}{*}{0.26} \\
\hline & Non-stable & 40 & $14(35)$ & $26(65)$ & \\
\hline \multirow{2}{*}{$\begin{array}{l}\text { Isolation } \\
\text { place }\end{array}$} & Home & 55 & $23(42)$ & $32(58)$ & \multirow{2}{*}{0.572} \\
\hline & Hospital & 05 & $1(20)$ & $4(80)$ & \\
\hline \multirow{3}{*}{$\begin{array}{l}\text { Isolation } \\
\text { days }\end{array}$} & Upto 14 & 27 & $7(26)$ & $20(74)$ & \multirow{3}{*}{0.12} \\
\hline & $15-20$ & 22 & $12(55)$ & $10(45)$ & \\
\hline & $>20$ & 11 & $5(45)$ & $6(55)$ & \\
\hline
\end{tabular}

In our study, the main predisposing factors leading to PTSD was ICU admission due to COVID-19. Out of 5 participants who were admitted in intensive care unit due to COVID-19, 4 (80\%) showed positive PTSD symptoms. Out of 42 patients who were fearful about serious complications related to COVID-19, 30 (71\%) showed signs of PTSD. One of the reasons for this fear was array of information by social media as 32 participants in our study faced difficulty because of social media and out of those 24 (75\%) showed PTSD symptoms. Out of 24 participants who had shortness of breath or decrease oxygen saturation during COVID-19 infection, 15 (63\%) patients suffered PTSD. Prior co-morbid were present in 24 participants 
overall, out of which 16 (67\%) showed PTSD symptoms.

Out of 45 participants who had positive history of family members and close friends affected with COVID-19, 27 (60\%) showed post-traumatic stress disorder. History of COVID related deaths and ICU admission of close family members and friends remain another predisposing factor as out of 27 participants who had positive history of family members and close friends' death affected with COVID-19, 19 (70\%) showed post-traumatic stress disorder symptoms. Out of 51 participants in our study had fear of transmitting the disease to their family members. Out of those 33 $(65 \%)$ suffered PTSD. Similarly, out of 22 participants who had historyof intensive care unit admission of family members and close friends effected with COVID$19,15(68 \%)$ showed post-traumatic stress disorder.

Table-II: Difficulties /fear related to COVID-19.

\begin{tabular}{|c|c|c|c|}
\hline & Total & $\begin{array}{l}\text { Non- } \\
\text { PTSD }\end{array}$ & PTSD \\
\hline $\begin{array}{l}\text { Difficulty of being in } \\
\text { isolation }\end{array}$ & 39 & $11(28 \%)$ & $28(72 \%)$ \\
\hline $\begin{array}{l}\text { Fear of transmission of disease to } \\
\text { family/close friends }\end{array}$ & 51 & $18(35 \%)$ & $33(65 \%)$ \\
\hline $\begin{array}{l}\text { Fear of serious complication } \\
\text { of COVID-19 }\end{array}$ & 42 & $12(29 \%)$ & $30(71 \%)$ \\
\hline Information by social media & 32 & $8(25 \%)$ & $24(75 \%)$ \\
\hline Uncertainty about future & 25 & $6(24 \%)$ & $19(76 \%)$ \\
\hline $\begin{array}{l}\text { Lack of social and financial } \\
\text { support }\end{array}$ & 9 & $1(11 \%)$ & $8(89 \%)$ \\
\hline $\begin{array}{l}\text { Lack of evidence based } \\
\text { treatment of COVID-19 }\end{array}$ & 18 & - & $\begin{array}{c}18 \\
(100 \%)\end{array}$ \\
\hline $\begin{array}{l}\text { Social stigma faced during } \\
\text { isolation/after recovery }\end{array}$ & 28 & $5(18 \%)$ & $23(82 \%)$ \\
\hline $\begin{array}{l}\text { Hopelessness and sleep } \\
\text { problems }\end{array}$ & 25 & $6(24 \%)$ & $19(76 \%)$ \\
\hline \multicolumn{4}{|c|}{$\begin{array}{l}\text { Table-III: Associtaed features with COVID-19 as possible } \\
\text { predisposing factor of PTSD. }\end{array}$} \\
\hline & Total & $\begin{array}{l}\text { Non- } \\
\text { PTSD }\end{array}$ & PTSD \\
\hline $\begin{array}{l}\text { Prior history of medical } \\
\text { comorbids }\end{array}$ & 24 & $8(33 \%)$ & $16(67 \%)$ \\
\hline $\begin{array}{l}\text { Sob/decrease oxygen } \\
\text { saturation }\end{array}$ & 24 & $9(38 \%)$ & $15(63 \%)$ \\
\hline $\begin{array}{l}\text { ICU admission due to } \\
\text { COVID-19 }\end{array}$ & 5 & $1(20 \%)$ & $4(80 \%)$ \\
\hline $\begin{array}{l}\text { Positive COVID test of } \\
\text { family members/friends }\end{array}$ & 45 & $18(40 \%)$ & $27(60 \%)$ \\
\hline $\begin{array}{l}\text { Icu admission of family } \\
\text { members/close friends }\end{array}$ & 22 & $7(32 \%)$ & $15(68 \%)$ \\
\hline $\begin{array}{l}\text { Any COVID related deaths } \\
\text { in family or close friends }\end{array}$ & 27 & $8(30 \%)$ & $19(70 \%)$ \\
\hline $\begin{array}{l}\text { History of premorbid } \\
\text { psychiatric illness }\end{array}$ & 7 & $1(14 \%)$ & $6(86 \%)$ \\
\hline
\end{tabular}

\section{DISCUSSION}

Pandemics or epidemics may have delayed profound psychological impact on patient's mental health. PTSD is a rigorous mental health condition caused by a frightening or scary event beyond the normal range of customary human experiences. ${ }^{12}$

A study done among SARS survivors regarding continuing psychiatric morbidities, discovered that PTSD was the most common long-term psychiatric problems as collective proportion of patients with PTSD was $47.8 \%$ after SARS. ${ }^{9}, 18$ This is comparable with frequency of PTSD in patients with COVID-19 infection observed in our study that is around $60 \%$.

There are certain variables that are associated with higher incidence of PTSD after some general disaster. ${ }^{16,17}$ Previous studies had shown that the females, the elderly and low-income groups are more susceptible to PTSD. The co morbidity of chronic psychological problems, lack of financial and social support etc. are possible risk factors. ${ }^{9}$ Results of our studies revealed slightly increased incidence of PTSD in female participants $(63 \%)$ as compared to male $(57 \%)$ and in participants with unstable socio economical background moreover elderly $(81 \%)$ and participants without profound social and financial support showed significantly higher incidence of PTSD (89\%). ${ }^{9}$

Similarly, results from a multicenter study revealed that pre-existing anxiety and depression were associated with a higher frequency of PTSD than that without any psychiatric problems. ${ }^{15}$ Our study results are comparable to this as it shows that $86 \%$ of the participants with pre COVID psychiatric problems showed symptoms and diagnosis of PTSD. While control of the pandemic and care of patients with COVID-19 are still the foremost assignment for health care workers, attention needs to be given for early intervention and prevention of PTSD among affected populations especially to those who are prone to develop PTSD later.

PTSD or long-term psychological effects related to COVID-19 pandemic specifically, could be grouped into three categories. The first is directly related to symptoms and traumatic treatment along with isolation. For example, shortness of breath, respiratory failure and other life-threatening symptoms leading to intensive care unit admission. ${ }^{11}$ In our study, the main predisposing factors leading to PTSD was ICU admission with PTSD frequency of (80\%). Even the fear of developing serious complication of COVID-19 was one of the leading factors that lead to PTSD later (70\%). 
Second group of is witnessing a family members or close friends who struggle against or who die of the infectious disease. ${ }^{11}$ WHO reports that almost 30-50\% of the people affected by a disaster will face psychological suffering due to facing injury or death of immediate family member. ${ }^{13}$ Similar to, our study results showed higher incident of PTSD in participants who had their family members and close friends effected with COVID-19. The frequency of PTSD was even higher in patients with COVID related ICU admission of family members $(68 \%)$ and COVID-19 related deaths in family $(70 \%)$.

Third is experiencing the possible fear of infection, social isolation, and stigmatization. All these can directly affect patients and their family members. ${ }^{11}$ In our study, $72 \%$ of patients who had difficulty of being in isolation developed PTSD later.

Considering that PTSD patients are atmore risk of suicidal ideation and suicidal attempts, health policies should formulate effective strategies to prevent PTSD and its resultant suicide. It is a concerning thought that people having PTSD after COVID-19 are susceptible to not pursue psychological care, due toscarcity of information, expensive mental health care, being fearful of stigmatization, and considering that they willget better with time. ${ }^{14}$

\section{ACKNOWLEDGEMENT}

We want to thanks all the administrative and paramedical staff of Creek General Hospital who helped us to complete this study.

\section{CONCLUSION}

PTSD can be observed as long-term psychiatric problem leading to significant morbidity and mortality in patients with COVID-19 infection. Strategies need to take into account to prevent PTSD and the related risk of suicide in upcoming time.

Conflict of Interest: None.

\section{Authors' Contribution}

KM: Manuscript writing, SF: Study design \& data analysis, IHU: Statistical analysis \& critical revision, AA: Data collection, OKT: Data collection, ZUN: Data collection.

\section{REFERENCES}

1. World Health Organization. Novel coronavirus (2019-nCoV) situation reports. 2020 [Internet] Available from: https://www. who.int/docs/default-source/corona-viruse/situation-reports/ 20200703-covid-19-sitrep-165.pdf?sfvrsn=b27a772e_6 Accessed: July 3, 2020.

2. Zhu N, Zhang $\mathrm{D}$, Wang $\mathrm{W}$. A novel coronavirus from patients with pneumonia in China, 2019. N Engl J Med 2020; 382(8): 727733.
3. Duan L, Zhu G. Psychological interventions for people affected by the COVID-19 epidemic. Lancet Psych 2020; 7(4): 300-302.

4. Batawi S, Tarazan N, Al-Raddadi R. Quality of life reported by survivors after hospitalization for middleeast respiratory syndrome (MERS). Health Qual Life Outcom 2019; 17(1):101-105.

5. Kim HC, Yoo SY, Lee BH, Lee SH, Shin HS. Psychiatric findings in suspected and confirmed middle east respiratory syndrome patients quarantined in hospital: a retrospective chart analysis. Psych Invest 2018; 15(4):355-360.

6. World Health Organization: Coronavirus disease 2019 (COVID19) Situation Report-112, [Internet] Available from: https:// www.who.int/emergencies/diseases/novel-coronavirus-019/ situation-reports. Accessed: 12 May 2020.

7. Sadock BJ, Sadock AV, Ruiz, editors. Kaplan and Sadock's comprehensive textbook of psychiatry. 10th ed. Philadelphia: Wolters Kluwer; 2017, Available at: https://www.amazon.com/ Kaplan-Sadocks-Comprehensive-Textbook-

Psychiatry/dp/1451100477

8. Inter-Agency Standing Committee (IASC). IASC Guidelines on Mental Health and Psychosocial Support in Emergency Settings. Geneva: IASC 2017, [Internet] Available at: https://www. who.int/mental_health/emergencies/guidelines_iasc_mental_h ealth_psychosocial_june_2007.pdf

9. Mak IWC, Chu CM, Pan PC. Long-term psychiatric morbidities among SARS survivors. Gen Hosp Psych 2009; 31(4):318-326.

10. WeissDS, Marmar CR. The Impact of Event Scale - Revised. In J Wilson \& TM Keane (Eds.), Assessing psychological trauma and PTSD (pp. 399-411). New York: Guilford.1996, https://psycnet. apa.org/record/2007-10108-010

11. Xiao, S, Luo, D, Xiao, Y. Survivors of COVID-19 are at high risk of posttraumatic stress disorder. Glob Health Res Policy. 2020 [Internet], Available at: https://doi.org/10.1186/s41256020-00155-2 Assessed: May 29, 2020.

12. Belrose C, Duffaud AM, Dutheil F, Trichereau J, Trousselard M. Challenges associated with the civilian reintegration of soldiers with chronic PTSD: A new approach integrating psychological resources and values in action reappropriation. Front Psych 2019; 737(9): 1-11.

13. Brooks S, Amlot R, Rubin GJ, Greenberg N. Psychological resilience and post-traumatic growth in disaster-exposed organisations: Overview of the literature. BMJ Military Health 2020; 166(1): 52-56.

14. Fuhr DC, Acarturk C, McGrath M, Ilkkursun Z, Sondorp E, Sijbrandij M, et al. Treatment gap and mental health service use among Syrian refugees in Sultanbeyli, Istanbul: a cross-sectional survey. Epidemiol Psych Sci 2019; 15(1): 29-e70.

15. Chew NWS, Lee GKH, Tan BYQ. A multinational, multicentre study on the psychological outcomes and associated physical symptoms amongst healthcare workers during COVID-19 outbreak. Brain Behav Immun 2020; 88(2):559-565.

16. Kun $\mathrm{P}$, Tong $\mathrm{X}$, Liu $\mathrm{Y}$. What are the determinants of post-traumatic stress disorder: age, gender, ethnicity or other? Evidence from 2008 Wenchuan earthquake. Public Health 2013; 127(7): 644-652.

17. Lowe SR, Bonumwezi JL, Valdespino-Hayden Z.Post-traumatic stress and depression in the aftermath of environmental disasters: a review of quantitative studies published in 2018. Curr Environ Health Rep 2019; 6(4):344-360.

18. Balanzá-Martínez V, Atienza-Carbonell B, Kapczinski F, De Boni RB. Lifestyle behaviours during the COVID-19-time to connect. Acta Psychiatr Scand 2020; 141: 399-400. 